\title{
Amsterdaml'og
}

\section{Geomechanics In Reservoir Modeling}

Akhil Garg (Indian Institute of Technology - Roorkee)

\section{SUMMARY}

None 


\section{Geomechanics In Reservoir Modeling}

\section{Amsterdaml'og}

GARG AKHIL, Indian Institute of Technology-Roorkee

Reservoir Modeling: The objective is the Generation of "3D Stiffness Model" for the whole reservoir space. It is achieved by estimating elastic parameters from 'well-log' data using standard petrophysics/rock physics transformations. Later the 1-D elastic parameters (along the well) are extrapolated using an efficient statistical technique to generate a 3D Stiffness model. This would help in understanding the 'Geomechanical behaviour' of layers in the reservoir. Production strategies, injection strategies can be efficiently undertaken using such a 'stiffness model'.

Reservoir Depletion: Geomechanics in reservoir modeling deals with the problems of compaction and or deformation of the reservoir rocks linked fluid flow. During production from a hydrocarbon reservoir, the formation pressure decreases and the effective stress increases resulting in the compaction/deformation of the reservoir rocks. This results in change of essential reservoir properties such as porosity, permeability, etc. Hence understanding the cause and behaviour of such changes is important. These changes can be estimated or analyzed using various techniques, like 4D Seismic, Multi-component seismic, Geometric seismic attributes and also stoneley waves.

Subsidence: Reservoir compaction due to hydrocarbon production and pore pressure depletion is common in unconsolidated reservoirs worldwide. Compaction may result in well failure, surface subsidence, and platform sinking. Surface subsidence is the differential sinking of the Earth's surface with respect to the surrounding terrain. Subsidence occurs in many parts of the world, in some cases as much as tens of meters within the short period of a few decades. We show the use of InSAR to measure surface subsidence occurred in oil fields due to production, and investigate the applications and implications of reservoir compaction and surface subsidence in reservoir monitoring. In this project, we will study how to use InSAR measured subsidence as an alternate or supplemental monitoring tool in addition to 4D seismic. 